\title{
Survey of Materials for Nanoskiving and Influence of the Cutting Process on the Nanostructures Produced
}

\section{Citation}

Lipomi, Darren J., Ramses V. Martinez, Robert M. Rioux, Ludovico Cademartiri, William F. Reus, and George M. Whitesides. 2010. Survey of materials for nanoskiving and influence of the cutting process on the nanostructures produced. ACS Applied Materials and Interfaces 2(9): 2503-2514.

\section{Published Version}

doi:10.1021/am100434g

\section{Permanent link}

http://nrs.harvard.edu/urn-3:HUL.InstRepos:9887631

\section{Terms of Use}

This article was downloaded from Harvard University's DASH repository, and is made available under the terms and conditions applicable to Open Access Policy Articles, as set forth at http:// nrs.harvard.edu/urn-3:HUL.InstRepos:dash.current.terms-of-use\#OAP

\section{Share Your Story}

The Harvard community has made this article openly available.

Please share how this access benefits you. Submit a story.

\section{Accessibility}


Survey of Materials for Nanoskiving and Influence of the Cutting Process on the Nanostructures Produced

Darren J. Lipomi, ${ }^{1}$ Ramses V. Martinez, ${ }^{1}$ Robert M. Rioux, ${ }^{2}$ Ludovico Cademartiri, ${ }^{1}$ William F. Reus, ${ }^{1}$ and George M. Whitesides ${ }^{1}$

${ }^{1}$ Department of Chemistry and Chemical Biology, Harvard University, 12 Oxford Street, Cambridge, $M A, 02138$

${ }^{2}$ Department of Chemical Engineering, 158 Fenske Laboratory, Pennsylvania State University, University Park, PA 16802-4400 


\begin{abstract}
This paper examines the factors that influence the quality of nanostructures fabricated by sectioning thin films with an ultramicrotome ("nanoskiving"). It surveys different materials (metals, ceramics, semiconductors, and conjugated polymers), deposition techniques, (evaporation, sputter deposition, electroless deposition, chemical-vapor deposition, solutionphase synthesis, and spin-coating), and geometries (nanowires or two-dimensional arrays of rings and crescents). It then correlates the extent of fragmentation of the nanostructures with the composition of the thin films, the methods used to deposit them, and the parameters used for sectioning. There are four major conclusions. i) Films of soft and compliant metals (those that have bulk values of hardness less than or equal to those of palladium, or $\leq 500 \mathrm{MPa}$ ) tend to remain intact upon sectioning, while hard and stiff metals (those that have values of hardness greater than or equal to those of platinum, or $\geq 500 \mathrm{MPa}$ ) tend to fragment. ii) All conjugated polymers tested form intact nanostructures. iii) The extent of fragmentation is lowest when the direction of cutting is perpendicular to the exposed edge of the embedded film. iv) The speed of cutting — from $0.1 \mathrm{~mm} / \mathrm{s}$ to $8 \mathrm{~mm} / \mathrm{s}$ - has no effect on the frequency of defects. Defects generated during sectioning include scoring from defects in the knife, delamination of the film from the matrix, and compression of the matrix. The materials tested were: aluminum, titanium, nickel, copper, palladium, silver, platinum, gold, lead, bismuth, germanium, silicon dioxide $\left(\mathrm{SiO}_{2}\right)$, alumina $\left(\mathrm{Al}_{2} \mathrm{O}_{3}\right)$, tin-doped indium oxide (ITO), lead sulfide nanocrystals, the semiconducting polymers MEH-PPV, P3HT, and BBL, and the conductive polymer PEDOT:PSS.
\end{abstract}




\section{Introduction}

This paper surveys materials for use in nanoskiving — a process of fabrication whose key step is sectioning planar or topographically patterned thin films with an ultramicrotome (Figure 1), ${ }^{1,2}$ and correlates their composition and method of deposition with the qualities of structures produced (e.g., morphology and extent of fragmentation). We examined two types of structures - long nanowires and two-dimensional (2D) arrays of circular or semicircular particles-formed by sectioning thin films for defects due to intrinsic mechanical properties of the materials (e.g., brittleness). We also explored the origin of defects due to artifacts of the sectioning process, and conclude that compression of the matrix, scoring due to chips in the edge of the knife, and delamination of the film from the matrix are the most important. Nanoskiving is useful for generating nanostructures for applications in electronics ${ }^{3}$ and optics, ${ }^{4,5}$ and has the potential to be used for manufacturing certain types of structures (e.g., nanowires and 2D arrays of nanostructures). The information in this paper will be useful to those concerned with designing processes for fabrication based on nanoskiving.

\section{Background}

Unconventional Nanofabrication. "Nanofabrication" generates structures with sizes of $\leq 100 \mathrm{~nm}$ in at least one lateral dimension. ${ }^{6,7}$ Most commercial nanofabrication takes place in the semiconductor industry, where the high-precision tools of electron-beam writing and photolithography dominate, and are likely to continue to do so for the foreseeable future. ${ }^{8,9}$ Many new applications for nanostructures, particularly in photonics, ${ }^{10}$ chemical ${ }^{11}$ and biological sensing, ${ }^{12,13}$ materials for energy conversion and storage, ${ }^{14,15}$ and organic electronic devices ${ }^{16}$ require structures that are simpler, and less expensive, than integrated circuits. Fabricating 
devices on non-planar, mechanically compliant, or disposable substrates could lead to important applications that motivate the development of "unconventional" methods of nanofabrication. ${ }^{10}$ Soft lithographic printing and molding, and other methods, have begun to fill these niches in research laboratories, and are expected to play important roles in manufacturing in the future. ${ }^{7}$

Nanoskiving. Nanoskiving is a technique for replicating nanostructures that substitutes "cutting" for "printing" or "molding". The process builds on two well-established technologies: i) methods of forming thin films (e.g., physical- and chemical-vapor deposition) and ii) patterning relief structures in polymers by molding (e.g., replica molding ${ }^{17,18}$ and nanoimprint lithography $\left.{ }^{19,20}\right)$. There are two general strategies to form nanostructures by nanoskiving: sectioning perpendicular to a planar thin film and sectioning parallel to a pattern of relief structures supporting a thin film. ${ }^{1}$

The first process (Figure 2) produces nanowires. ${ }^{21}$ Stacking and sectioning multiple films, separated by sacrificial layers (e.g., polymers or $\mathrm{SiO}_{2}$ ), which can be etched in a later step, can produce closely spaced parallel nanowires. ${ }^{22}$ Topographic patterning can introduce angles into these nanowires to form simple elements for nanoelectronics, such as parallel electrodes. ${ }^{3}$ Patterning the thin film into stripes, and sectioning perpendicular to the stripes, can produce nanowires with well-defined lengths and spacings. ${ }^{23}$ The second process (Figure 3 ) produces 2D arrays of nanostructures. The outlines of the molded features define the geometries of the structures produced by sectioning. ${ }^{5}$

Ultramicrotomy. The microtome was invented in the 1770 s to section specimens of wood for microscopy. ${ }^{24}$ Microtomy, the practice of generating thin sections for analysis, has since developed alongside microscopy. ${ }^{25}$ The invention of electron microscopy (EM) in the 1950s motivated the development of the ultramicrotome, an instrument that can section 
specimens into slabs $<100 \mathrm{~nm}$ in thickness under ambient conditions. ${ }^{25}$ Ultramicrotomy is ubiquitous in histology and polymeric materials science. In the science of hard materials, it is a complement to the more common techniques for the preparation of samples of ion thinning and electropolishing. ${ }^{26}$ When equipped with a diamond knife, the ultramicrotome can section even hard materials. Examples include: industrial alumina; ${ }^{27}$ nanocrystalline pure elements, alloys, and ceramics; ${ }^{28}$ diamond films; ${ }^{29}$ steel sheets; $;{ }^{30}$ and stacked layers of semiconductors. ${ }^{31}$

\section{Comparison of Nanoskiving with Materials Ultramicrotomy. Nanoskiving can be} treated as ultramicrotomy of materials having the goal of generating functional nanostructures, rather than of preparing specimens for EM. There are at least four other important differences. (1) In materials ultramicrotomy, the embedded specimen is usually a bulk sample. In nanoskiving, the embedded specimen is usually a thin film. (2) In materials ultramicrotomy, the requirement of transmission of electrons in EM imposes a limit on the thickness of sections to < $100 \mathrm{~nm}$. In nanoskiving, sections can be $30 \mathrm{~nm}-10 \mu \mathrm{m}$ thick, or greater. (3) In materials ultramicrotomy, small-area sections $(<200 \mu \mathrm{m}$ in width) are easier to obtain than large-area sections, because the force per unit length exerted by the knife on the facet of a block is greater for small facets than for large facets, and because it is easier to maneuver a small facet to an unworn region of the knife. ${ }^{32}$ In nanoskiving, it is often desirable to fabricate arrays of nanostructures over as large an area as possible $\left(\geq 1 \mathrm{~mm}^{2}\right)$. (4) In materials ultramicrotomy, extensively fractured specimens of brittle materials or specimens damaged by artifacts of the sectioning process can yield fragments that are large enough for analysis. In nanoskiving, any fracturing can be catastrophic, and fracturing limits the materials that can be used. An understanding of the properties of materials that make them amenable to nanoskiving would enable it to be applied more broadly than it now is. 
Mechanism of Sectioning. Sectioning involves a complicated interplay of processes: compression of the sample; tension perpendicular to the plane of sectioning; formation of new surfaces; bending, as the slab reorients from vertical to horizontal; shearing stress; friction of the slabs on the knife; and heat. ${ }^{33}$ There are two possible mechanisms for the sectioning process, i) true, or shear, sectioning, in which the edge of the knife maintains intimate contact with both the facet of the block and the nascent slab (Figure 4a), and ii) a mechanism of crack initiation and propagation, in which the knife splits or cleaves the block (Figure 4b). There is evidence for both processes, and each process can be present to different degrees in the same epoxy block, because each material within the block (or different grains or phases within the same material) can respond differently to the force of the knife (e.g., cleavage vs. shattering).

Processes resembling true sectioning (4a) appear to dominate for metals and alloys. ${ }^{32}$ The shearing of the slab produces shear lamellae in the sections, perpendicular to the direction of cutting. Microtomed sections of aluminum (thickness $=500 \mathrm{~nm}$ ) and micromachined chips of steel display this morphology, which is characteristic of unstable plastic flow in metals and alloys. $^{32}$ The appearance of scoring on both the top and bottom surfaces of slabs of some specimens also suggests a mechanism like that of $4 \mathrm{a}^{32}$

Processes of crack initiation and propagation (4b) appear to operate for brittle materials such as minerals and ceramics. ${ }^{26}$ The knife initiates a crack, which follows the path of weakest molecular strength. ${ }^{34}$ Acetarin et al. argued in favor of some degree of crack propagation for all specimens because of the observation of craze formation ${ }^{33}$ within slabs and also because it is impossible for a knife to be infinitely sharp — the radius of curvature of diamond knives is typically $3-6 \mathrm{~nm}$, or a few tens of atoms. ${ }^{35}$ The extent to which crack propagation extends ahead of the knife edge depends on the amount of energy the sample can absorb by plastic flow 
prior to fracture (as in a measurement of hardness with a sharp indenter). Jésior postulated that the distance between the crack and knife increases with increasing hardness of the specimen. He argued that the farther the crack propagates ahead of the knife, the larger the radius over which the slab has to bend to go from vertical to horizontal, and thus the smaller the compressive stress on the slab while bending. ${ }^{34}$

The orientation of cleavage planes in crystalline samples also determines the extent of fragmentation upon sectioning, as Antonovsky observed in samples of alumina. ${ }^{27}$ True sectioning and crack propagation can apparently operate at the same time on different grains within the same specimen. In samples of high-strength steel, Malis observed regions with shear lamellae, which are consistent with true sectioning (4a), as well as large defect-free regions, which is evidence of cleavage (4b). ${ }^{32}$ Ultramicrotomes, when equipped with sensors, have also been used as analytical tools to measure fracture toughness and other properties of specimens. ${ }^{36}$

Mechanical Properties of Thin Films. The ability to obtain intact nanostructures after sectioning depends on the mechanical properties of the film. These properties are strongly influenced by the morphology of the film, which depends on the technique used for deposition. ${ }^{37}$ In general, evaporated metallic films are polycrystalline and assume a columnar grain structure whose columns are perpendicular to the substrate. ${ }^{37}$ Evaporation of covalent solids, such as silicon and germanium, forms amorphous films. ${ }^{37}$ Evaporated films of oxides and nitrides can be depleted of oxygen and nitrogen. Compared to evaporation, sputtering-coating generally affords the user more control over the morphology of the thin film, and also preserves the stoichiometry.

Evaporated metallic films can be up to 100 times harder and stronger more than their bulk, annealed counterparts. ${ }^{37}$ These polycrystalline films have two characteristics that are responsible for their hardness and strength. (1) Work hardening: high densities of dislocations 
$\left(10^{10}-10^{12} \mathrm{~cm}^{-2}\right)$ correspond to those of extensively worked bulk metals. (2) Grain-boundary strengthening: the sizes of grains in thin films $(10-1000 \mathrm{~nm})$ can be a few orders of magnitude smaller than those of bulk samples. Work hardening and grain-boundary strengthening combine to produce films in which the mobilities of dislocations is impeded, plastic flow is restricted, and thus increased strength, hardness, and brittleness. ${ }^{37}$

Scope. There is not an absolute criterion for the successful sectioning of materials by ultramicrotomy. This paper should provide practical information for the selection of materials and processes of deposition. It also describes the artifacts of the sectioning process (and how to avoid them), and their influence on the nanostructures produced. For reviews of the practical aspects of ultramicrotomy, see Goldstein and Newbury; ${ }^{38}$ for a review of ultramicrotomy applied to the science of inorganic materials, see Malis and Steele; ${ }^{32}$ for a survey of embedding resins, see Acetarin et al.;3 for a perspective on the role of ultramicrotomy for biological applications, see Villiger; ${ }^{39}$ and for a history of ultramicrotomy, see Pease and Porter. ${ }^{25}$

\section{Experimental Design}

Selection of Thin-Film Materials. We sectioned films of several different materials, including metals, semiconductors, metal oxides, conjugated polymers (semiconducting and conducting), and films of semiconductor nanocrystals. The materials chosen occupy a range of different mechanical properties, and most have not been used with nanoskiving before.

Selection of Processes of Deposition. For metals, our primary method of deposition was electron-beam (e-beam) evaporation. ${ }^{40}$ We used sputter-deposition for films of platinum and ceramic materials, to try to control the amount of fragmentation in the nanostructures produced. We synthesized microplates $(d \sim 10-70 \mu \mathrm{m})$ of single-crystalline gold, ${ }^{41}$ which we sectioned 
into nanowires. Electroless deposition provided amorphous films of nickel on epoxy substrates. We deposited ceramic films by evaporation, sputter deposition, or plasma-enhanced chemicalvapor deposition (PECVD). We deposited films of conjugated polymers and semiconductor nanocrystals by spin-coating and drop-casting. We deposited polypyrrole electrochemically.

Fabrication of Nanowires by Sectioning Thin Films. A stringent test that enabled us to determine the applicability of materials for nanoskiving was to form long nanowires $(>100 \mu \mathrm{m})$ by sectioning thin films, and to determine the extent of fragmentation by scanning electron microscopy (SEM). We measured electrical conductivity to verify the continuity of some of the nanowires. We used the process summarized in Figure 2 for all of these experiments. We sectioned the thin films with a direction of cutting perpendicular to the edge of the thin film. In this orientation, the action of the knife compressed the slab along the short axis of the nanowire. We also determined the effect of compression on the frequency of defects when the direction of cutting was parallel to the edge of embedded film for some metals.

\section{Fabrication of 2D Arrays of Crescents and Rings by Sectioning Arrays of}

Nanoposts. We fabricated arrays of simple semicircular and circular structures using a process summarized in Figure 3, which began by forming an array of epoxy nanoposts by soft lithography. ${ }^{42}$ Line-of-sight deposition of metal on the sidewalls of these posts, followed by embedding, and sectioning with the ultramicrotome, produced metallic crescent-shaped nanostructures. Conformal coating by a sputtering process, followed by embedding and sectioning, produced arrays of rings. Examination of the structures produced by these processes provided i) the yield of unbroken structures and ii) the rate of compression of the axis of the array parallel to the direction of cutting. 
Selection of Embedding Resin. An embedding resin should have i) a relatively high value of elastic modulus ( $\sim 3 \mathrm{GPa}$, a block that is too elastic deflects from the knife, rather than cleave), and ii) a high yield stress after which the material undergoes plastic deformation ( 70 $\mathrm{MPa}$, otherwise the slab will deform upon sectioning). ${ }^{33}$ Epoxy resins such as Epon, Araldite 502, and Epo-Fix (which is used for all experiments in this paper, unless otherwise noted) possess most of the properties required for good sectioning. Epo-Fix (Electron Microscopy Sciences) is a typical two-part epoxy containing polymers of bisphenol-A diglycidyl ether and triethylene tetraamine. It has excellent adhesion to most materials tested, and can be cured at room temperature (the best results were achieved for $60^{\circ} \mathrm{C}$ for $2 \mathrm{~h}$ ) from a prepolymer with relatively low viscosity $\left(5 \times 10^{-2} \mathrm{~Pa} \cdot \mathrm{s}\right)$, which facilitates impregnation of porous samples. EpoFix is relatively hard $\left(75\right.$ Shore D) ${ }^{43}$ and stiff (flexural modulus $=2.4 \mathrm{GPa}$ ). Epo-Fix exhibits significant compression along the direction of cutting (15-20\% for $100 \mathrm{~nm}$ sections). This rate of compression ensured that the thin films would have to be sufficiently soft and compliant to accommodate the strain due to the compression of the embedding resin, and thus imposed a strict criterion for the success or failure of a given thin film.

Ultramicrotome and Knife. We used a Leica Ultracut UCT equipped with a $35^{\circ}$ diamond knife for all applications (Diatome Ultra $35^{\circ}$ ). We and others found less compression and delamination of films from the resin with $35^{\circ}$ knives than with $45^{\circ}$ knives. $^{26}$

\section{Results and Discussion}

Fabrication of Nanowires by Sectioning Thin Metallic Films. We deposited, embedded, and sectioned a series of ten different metallic thin films by e-beam evaporation: aluminum, titanium, nickel, copper, palladium, silver, platinum, gold, lead, and bismuth. We 
deposited three additional films of these materials using different techniques - a polycrystalline film of platinum by sputter deposition, single-crystalline microplates of gold by growth from solution, ${ }^{41}$ and an amorphous film of nickel by electroless deposition. We deposited most films with a thickness of $50-100 \mathrm{~nm}$, and sectioned them with a programmed thickness of $80 \mathrm{~nm}$ at a velocity of $1 \mathrm{~mm} / \mathrm{s}$, with a direction of cutting perpendicular to the plane of the film. The substrate for deposition of films of silver, gold, palladium, and platinum was the polished surface of a silicon wafer. After deposition, we transferred the film to epoxy by puddle-casting an epoxy prepolymer, curing it, and peeling off the solid epoxy, along with the metallic film ("template stripping"). ${ }^{44,45}$ This method produced very flat films (rms roughness $<1 \mathrm{~nm}$ ) on the surface templated by the silicon wafer. ${ }^{45}$ We deposited all other materials directly on the flat side (rms roughness $=0.5 \mathrm{~nm}$ ) of a cured epoxy substrate, prepared by puddle-casting the prepolymer against the polished side of a silicon wafer. ${ }^{4}$ Figure 5 shows representative spans of several of the nanowires produced by sectioning these films. Aluminum (5a), nickel (5c), copper (5d), palladium (5e), silver (5f), gold (5i), lead (5k), and bismuth (5l) formed nanowires with long unbroken spans, as determined by SEM. Most nanowires were $300 \mu \mathrm{m}-1 \mathrm{~mm}$ long. We defined this length loosely by cutting with a razor blade (see Figure 2, step 2).

Electrical Conductivity of Long Gold Nanowires. In order to verify that inspection by SEM was an accurate method of determining physical continuity, we measured the electrical conductivity of the longest nanowires produced: a gold nanowire with dimensions of $l=1.8 \mathrm{~mm}$, $w=80 \mathrm{~nm}, h=120 \mathrm{~nm}$. Figure 6 shows an SEM image and the electrical characteristics of a representative span of the nanowire. Based on these dimensions and the current at $\pm 10 \mathrm{mV}$, we calculated a value of conductivity of $3.0 \times 10^{5} \Omega^{-1} \mathrm{~cm}^{-1}$ (the literature value for bulk gold is $4.5 \times$ 
$10^{5} \Omega^{-1} \mathrm{~cm}^{-1}$ ). This experiment demonstrates that the process of sectioning introduces relatively few defects that are electronically significant into the nanowires.

\section{Correlation of Bulk Properties of Materials with Fragmentation of Thin Films.}

Sectioning films of titanium (5b) and platinum (5g) produced fragmented nanowires. We verified, by SEM, that the films were intact prior to embedding and sectioning. In general, metals that formed intact nanowires upon sectioning were soft, compliant, and low-melting, based on values of bulk properties in the literature. Those that fragmented were hard, rigid, and highmelting. Metals as soft or softer than palladium — that is, metals with bulk values of hardness of the less than approximately $500 \mathrm{MPa}$ (Vickers hardness number)_formed intact nanowires. The next hardest metal tested, platinum, broke into fragments with average lengths of $10 \mu \mathrm{m}(5 \mathrm{~g})$. Evaporation of nickel produced an exceptionally resilient film by evaporation, which did not fragment. Titanium, the hardest material tested, fragmented extensively (5b).

Effect of Direction and Speed of Cutting on Fragmentation. The orientation of an embedded thin film with respect to the direction of cutting had a profound effect on the frequency of defects and the morphology of the nanostructures that were formed. For example, sectioning with a direction of cutting perpendicular to the edge of an evaporated film of nickel formed unfragmented nanowires $(5 \mathrm{c})$, while sectioning parallel to the edge of the same film produced fragmented nanowires whose segments had lengths of $10-20 \mu \mathrm{m}$. We attribute the higher frequency of defects in nanowires oriented parallel to the direction of cutting to compressive stress along the longitudinal axis of the nanowires. The breaks in the nanowires do not appear at regular intervals. This observation suggests that randomly located defects and thin areas (which arise from uneven chemical or physical vapor deposition) influence the sites of fracture. Evaporated films of gold, palladium, nickel, and platinum — which displayed no or little 
fragmentation using a perpendicular direction of cutting-yielded fragments with lengths of approximately $100 \mu \mathrm{m}, 10 \mu \mathrm{m}, 10 \mu \mathrm{m}$, and $1 \mu \mathrm{m}$, when sectioned parallel to the edge of the film.

In addition to increasing the rate of defects in the nanowires, a direction of cutting parallel to the edge of the film also imparted a roughened morphology to the nanowires. Figures $7 \mathrm{a}$ and $7 \mathrm{~b}$ show the two relative orientations used in this paper between the direction of cutting and the edge of the embedded film: perpendicular (7a) and parallel (7b). Figures $7 \mathrm{c}$ and $7 \mathrm{~b}$ show two palladium nanowires obtained from the same embedded film, but sectioned from orthogonal directions. The insets are close-up images that show the smooth microstructure of the film cut perpendicular to its edge (7c), and the rough microstructure of the nanowire cut parallel to its edge (7d). The rough microstructure in $7 \mathrm{~d}$ resembles the shear lamellae (parallel to the short axis of the nanowire) observed in microtomed foils of bulk metals. ${ }^{32}$

Jésior published a series of papers on compression in ultramicrotomy, and how to avoid it. ${ }^{34,46} \mathrm{He}$ observed that the rate of compression of latex spheres was independent of the compression of the epoxy matrix. The soft latex spheres formed ellipses upon sectioning, and delaminated from the edges of the epoxy matrix. ${ }^{46}$ In our system, however, delamination of metallic films from the epoxy matrix was rare. Adhesion of metallic films to a compressible embedding resin (17\% for 100-nm slabs of Epo-Fix) forces the nanowire to compress at the same rate as the matrix, and could be a factor responsible for the high rate of defects observed in hard and stiff films whose edges were oriented parallel to the direction of cutting.

Jésior also observed that compression is independent of the speed of cutting. ${ }^{34}$ Figure $7 \mathrm{e}$ shows a platinum nanowire oriented parallel to the direction of cutting using six speeds from 0.1 $-10 \mathrm{~mm} / \mathrm{s}$. We found that the frequency of defects was independent of the speed of cutting, from $0.1-8 \mathrm{~mm} / \mathrm{s}$. (The highest speed tested, $10 \mathrm{~mm} / \mathrm{s}$, actually decreased the frequency of defects. 
At this speed, the nanowire, and the surrounding epoxy, accommodated the compressive strain by buckling into long-range, wave-like distortions. See $7 \mathrm{e}$, " $10 \mathrm{~mm} / \mathrm{s} "$.

Fabrication of Platinum Nanowires from Sputter-Deposited Films. Sputter-deposition can yield films with different morphologies: from polycrystalline metallic films with a range of mean grain size, to metallic glasses, and oxide films with stoichiometry that matches that of the source material. ${ }^{37} \mathrm{We}$ found that a sputter-coated film of platinum was much more resistant to fracture than an evaporated film of the same thickness (50 nm, compare Figure $5 \mathrm{~g}$ and $5 \mathrm{~h}$ ). While the evaporated film of platinum formed fragmented nanowires with $1-\mu \mathrm{m}$ segments using a direction of cutting parallel to the edge of the film, the sputter-deposited film fragmented into $10-\mu \mathrm{m}$ segments. We attribute the greater resilience of the sputtered film to morphological characteristics (density of dislocations and the sizes of grains). We expect the parameters of deposition can be tuned to reduce the rate of fragmentation upon sectioning hard materials.

Fabrication of Gold Nanowires from Single-Crystalline Microplates. Polycrystalline films, deposited by physical vapor deposition, become polycrystalline nanostructures upon sectioning. Many applications however, require structures with smooth surfaces (e.g., metallic nanowires for plasmonic waveguiding). ${ }^{47,48}$ There is a family of procedures for the synthesis of single-crystalline metallic micro- and nanoparticles that provide control over the shapes and the compositions of these particles. ${ }^{49}$ Our laboratory previously reported the plasmonic properties of single-crystalline gold nanowires formed by nanoskiving single-crystalline microplates grown by solution-phase synthesis. ${ }^{4,41}$ Observation of lattice fringes by TEM indicated that the crystallinity of the microplates was intact after sectioning. We have never observed fragmentation of single-crystalline gold nanowires, even those with lengths up to $50 \mu \mathrm{m}$ (the 
longest we have produced). Comparing Figures $5 \mathrm{i}$ and $5 \mathrm{j}$ illustrates the difference between polycrystalline and single-crystalline nanowires.

Fabrication of Nickel Nanowires from Amorphous Films. We also deposited and sectioned an amorphous nickel film by electroless deposition. While this film formed an unfragmented nanowire with a direction of cutting perpendicular to the embedded film, it broke into fragments $500 \mathrm{~nm}-1 \mu \mathrm{m}$ long when cut with a parallel direction. These fragments were an order of magnitude smaller than those derived from the evaporated film of nickel. Correlation of the microstructures of the thin films, as determined by TEM, will be required to understand the extent to which morphology influences the extent of fragmentation.

Fabrication of Semiconductor Nanowires from Evaporated Films. Covalent solids, such as silicon and germanium, form amorphous films when evaporated. The most important result from the survey of polycrystalline metallic films was that soft materials form relatively soft thin films, which tend to form intact nanostructures upon sectioning. Initial results suggest that this generalization holds true for amorphous semiconductors, as well as for metals. We sectioned films of germanium and silicon using a direction of cutting perpendicular to the edge of the embedded thin film. The germanium film formed intact nanowires over lengths of $>30$ $\mu \mathrm{m}$ (Figure 8a), while the silicon film fractured extensively $(8 b)$.

Fabrication of Nanowires from Films of Ceramic Films. Films of oxides, aluminum oxide $\left(\mathrm{Al}_{2} \mathrm{O}_{3}\right)$, silicon dioxide $\left(\mathrm{SiO}_{2}\right)$, and tin-doped indium oxide (ITO), prepared by evaporation, sputter deposition, and PECVD, were the hardest materials we tested (Figures $8 \mathrm{c}-$ $8 \mathrm{~g})$. The only film that formed intact nanowires was a sputter-coated film of $\mathrm{SiO}_{2}$. Applications that require long, intact spans of ceramic materials should be prepared using a softer material that can be converted to the film in its final form. For example, thermal oxidation and calcination 
can, in principle, convert soft metallic films or sol-gel precursors-which section easily_into the desired ceramic materials. ${ }^{50}$

\section{Fabrication of Nanostructures of Solution-Processed Materials: Semiconductor}

Nanocrystals and Conjugated Polymers. Organic polymers and polymer-like materials are

among the easiest materials to section with the ultramicrotome. ${ }^{22}$ Figure $8 \mathrm{~h}$ is a nanowire derived from sectioning a spin-coated film of oleylamine-capped lead sulfide $(\mathrm{PbS})$ nanocrystals, ${ }^{51}$ which formed long, intact segments. Figures $8 \mathrm{i}-81$ are examples of conjugated (semiconducting and conducting) polymers: poly(3-hexylthiophene) (P3HT, 8i), poly(3,4-ethylenedioxythiophene) poly(styrenesulfonate) (PEDOT:PSS, 8j), poly(benzimidazobenzophenantrholine ladder) (BBL, 8k), and poly(2-methoxy-5-(2'-ethyl-hexyloxy)-1,4-phenylene vinylene) (MEH-PPV, 81). All of these materials formed intact nanowires regardless of the orientation of cutting.

Table 1 summarizes the materials, methods of deposition, and average intact spans of each nanowire produced by nanoskiving. Entries labeled with an asterisk $(*)$ indicate that the nanowire did not fragment when sectioned with a direction of cutting normal to the plane of the film, as determined by inspection of the entire length of the nanowire by SEM. For these unbroken nanowires, the minimum span reported in the table corresponds to the longest span $(\geq$ $30 \mu \mathrm{m}$ in the center of the nanowire) that could be verified as unbroken in a single, highresolution SEM image. For all other entries, we calculated the average span by dividing the length of a representative span of the nanowire of at least $30 \mu \mathrm{m}$ by the number of fragments. 
Table 1. Summary of the materials, methods of deposition, and average intact spans of the nanowires formed by nanoskiving thin films.

\begin{tabular}{|c|c|c|}
\hline Material & $\begin{array}{l}\text { Method of } \\
\text { Deposition }\end{array}$ & $\begin{array}{l}\text { Avg. Span } \\
(\mu \mathrm{m})\end{array}$ \\
\hline $\mathrm{Al}^{*}$ & evaporation & $>40$ \\
\hline $\mathrm{Ti}$ & evaporation & 1 \\
\hline $\mathrm{Ni}^{*}$ & evaporation & $>40$ \\
\hline $\mathrm{Ni}^{*}$ & electroless deposition & $>30$ \\
\hline $\mathrm{Cu}^{*}$ & evaporation & $>30$ \\
\hline $\mathrm{Pd}^{*}$ & evaporation & $>100$ \\
\hline $\mathrm{Ag}^{*}$ & evaporation & $>50$ \\
\hline $\mathrm{Pt}$ & evaporation & 10 \\
\hline $\mathrm{Pt}^{*}$ & sputter-deposition & $>120$ \\
\hline $\mathrm{Au}^{*}$ & evaporation & $>80$ \\
\hline $\mathrm{Au}^{*}$ & chemical growth & $>50$ \\
\hline $\mathrm{Pb}^{*}$ & evaporation & $>30$ \\
\hline $\mathrm{Bi}^{*}$ & evaporation & $>40$ \\
\hline $\mathrm{Si}$ & evaporation & 5 \\
\hline $\mathrm{Ge}^{*}$ & evaporation & $>30$ \\
\hline $\mathrm{SiO}_{2}$ & evaporation & 10 \\
\hline $\mathrm{SiO}_{2} *$ & sputter-deposition & $>20$ \\
\hline $\mathrm{SiO}_{2}$ & PECVD & 5 \\
\hline $\mathrm{Al}_{2} \mathrm{O}_{3}$ & evaporation & 1 \\
\hline $\mathrm{Al}_{2} \mathrm{O}_{3}$ & sputter-deposition & 4 \\
\hline ITO & evaporation & 10 \\
\hline ITO & sputter-deposition & 2 \\
\hline P3HT* & spin-coating & $>50$ \\
\hline MEH-PPV* & spin-coating & $>100$ \\
\hline BBL* & spin-coating & $>50$ \\
\hline PEDOT:PSS* & spin-coating & $>40$ \\
\hline $\mathrm{PbS} *$ & spin-coating & $>60$ \\
\hline
\end{tabular}

*Indicates unbroken nanowires over the range examined.

Fabrication of 2D Arrays of Rings and Crescents. One of the most promising uses of nanoskiving is the fabrication and replication of 2D arrays of nanostructures embedded in thin slabs, which can be transferred to another substrate, ${ }^{52}$ for optics or other applications. ${ }^{5}$ Figure 3 summarizes the procedure used, which we reported previously. ${ }^{53}$ Figure 9 a shows an array of epoxy nanoposts, in which the sidewalls are partially coated with gold. Embedding these 
metalized posts in epoxy and sectioning parallel to the plane of the array produced 2D arrays of metallic nanostructures. The two most deleterious artifacts of mechanical sectioning that manifest themselves in 2D arrays formed by nanoskiving are i) fracture of individual structures and ii) compression of square arrays into rectangular arrays.

Yield of Intact Nanostructures in 2D Arrays. Figure 9b shows an array of platinum crescents. The yield of intact nanostructures was 93\%. Of 320 crescents in the array shown, nine were broken in the center (see lower inset), and thirteen were broken at the tips. Figure 9c shows counterfacing silver and silicon crescents patterned in the same plane. We did not find any broken structures in the array. The high yield ( $>99 \%)$ of intact silicon crescents is unexpected, because the planar film of silicon, deposited using the same conditions of evaporation, was extensively fragmented when cut into a nanowire (see Figure 8b). A possible explanation is that small particles are not subject to long-range tensile stress that could contribute to fragmentation of nanowires. Table 2 summarizes the results of $2 \mathrm{D}$ arrays we have fabricated using previously published procedures. ${ }^{53}$

Table 2. Table summarizing the materials, methods of deposition, geometries, and yields of twodimensional arrays of nanostructures.

\begin{tabular}{|c|c|c|c|}
\hline Material & $\begin{array}{l}\text { Method of } \\
\text { Deposition }\end{array}$ & Geometry & $\begin{array}{l}\text { Yield } \\
(\%)\end{array}$ \\
\hline $\mathrm{Si}^{*}$ & evaporation & crescents & $>99.7$ \\
\hline $\mathrm{Pd}^{*}$ & evaporation & crescents & $>99.7$ \\
\hline $\mathrm{Ag}^{*}$ & evaporation & crescents & $>99.7$ \\
\hline $\mathrm{Pt}$ & evaporation & crescents & 93.1 \\
\hline $\mathrm{Au}$ & evaporation & crescents & 99.9 \\
\hline $\mathrm{Au}^{*}$ & sputter-deposition & rings & $>99.7$ \\
\hline $\begin{array}{l}\text { Polypyrrole* } \\
\mathrm{PbS}\end{array}$ & electrodeposition & rings & $>99.8$ \\
\hline $\begin{array}{l}\text { nanocrystals } \\
\text { 'Indicates unfr }\end{array}$ & $\begin{array}{l}\text { drop-casting } \\
\text { ented nanostructu }\end{array}$ & rings & 97.5 \\
\hline
\end{tabular}

Compression of 2D Arrays. The second effect of the sectioning process that is relevant to some applications is the compression of the array along the direction of cutting. We formed an 
array of gold crescents and measured the dimensions of the array and the angle between the axes (Figure 9d). The original array of posts, from which we cut this array of crescents, was square with a pitch of $2 \mu \mathrm{m}$ between features. After sectioning (thickness $=100 \mathrm{~nm}$ ) using a randomly selected direction of cutting, we observed a shortening of both the vertical axis to $1.65 \mu \mathrm{m}$ and the horizontal axis to $1.9 \mu \mathrm{m}$. We measured a direction of cutting of $73^{\circ}$ from the horizontal row of crescents, as determined by a score, which was created by a defect in the knife and parallel to the direction of cutting. Because the direction of cutting was not parallel to either axis of the array, the compression skewed the array such that the unit cells deformed from square to diamond-shaped, with angles of $88.7^{\circ}$ and $91.3^{\circ}$. The total compression in the direction of cutting was $17 \%$. A survey of embedding resins led us to perform the same experiment with another epoxy, UVO-114 (a UV-curable resin obtained from Epoxy Technologies), and we measured $8 \%$ compression. (Through the course of the experiments described in this paper, and others, UVO-114 became our preferred resin for nanoskiving.) In general, the rate of compression is decreases with thickness of the section and the hardness of the resin. ${ }^{34}$

We summarized our findings and made predictions regarding the applicability of materials we have not yet tested in Figure 10. We assumed all metallic films were polycrystalline and all covalent solids were amorphous. Materials labeled "intact" are those that displayed no visible fragmentation, or large unbroken spans when cutting nanowires perpendicular to the plane of the embedded thin film. Films labeled "fragmented" fractured extensively into segments $<10 \mu \mathrm{m}$. Those labeled "borderline" are films whose rate of fragmentation depended strongly on the method of deposition, the size and geometry of the structure (e.g., nanowires or crescents), and the orientation of the thin film with respect to the direction of cutting. We extrapolated our observations to make predictions for materials that we did not test, or for which we did not have 
enough data. In the case of relatively hard, d-block metals, our predictions are conservative; while we predict most would fragment, it might be possible to optimize the recipe for deposition to form films soft enough to promote a high yield of unfragmented nanostructures. In the case of alkali and alkaline earth metals, we based our predictions on mechanical properties alone, and assumed that these films could be deposited and sectioned in an inert, dry environment. In addition to the materials in Tables 1 and 2, we sectioned chips ( $\sim 10 \mu \mathrm{m}$ thick) of highly oriented pyrolytic graphite. This material produced large intact spans of parallel plates when sectioned with a direction of cutting perpendicular to the edge of the chip; when sectioned parallel to the edge of the chip, the sample fractured extensively, into $\sim 1 \mu \mathrm{m}$ fragments. We thus labeled graphite as "borderline" in Figure 10.

Scoring. Chips in the edge of the diamond knife score the epoxy slabs and damage embedded structures in the paths of the scoring. A freshly sharpened knife contains no chips. As the knife is used, contact with hard material (commonly small inorganic dust particles from the laboratory, steel from the razor blade during trimming of the block face, or particularly hard samples) breaks microscopic pieces from knife. ${ }^{32}$ These chips are inevitable, and knives must be re-sharpened after $6-12$ months of normal use, at about half the cost of a new knife. Scoring was visible under dark-field optical microscopy, or by SEM (Figure 11a). Figure 11b shows a fracture caused by scoring in an aluminum nanowire. A region of delamination, where the silicon substrate is visible, accompanied the fracture. Scoring provides an exact marker of the direction of cutting on the surface of the epoxy slab, and can be useful in distinguishing fractures due to a damaged knife from those due to the brittleness of the thin films.

Delamination. Adhesion of an embedded film to the epoxy matrix provides stability to the nanostructures during the process of sectioning. Distortion caused by delamination of the 
films from the epoxy matrix can impose tensile stress on nanostructures. The structures have higher tendencies to break in regions of delamination than in regions in which the matrix supports the embedded film on all sides. We observed the least amount of delamination by embedding freshly deposited films. Films that were exposed to the ambient atmosphere for several days tended to delaminate upon sectioning because of physisorption of adventitious organic material from the ambient air. A brief $(\sim 5 \mathrm{~s})$ exposure to an air plasma removed adventitious organic material from metals such as gold, which would not be oxidized by plasma. Figure 11c shows a delaminated region in an epoxy slab containing a nickel nanowire. The delaminated regions extend for several microns, and contained the only fracturing we observed.

Chatter. Chatter is another artifact of ultramicrotomy, in which vibrations in the room or generated by friction between the knife and the sample produce parallel lines in the slab parallel to the edge of the knife. The effect is exacerbated when the knife is not securely fixed in the chuck. We rarely observed instances of chatter in these experiments, and direct the interested reader to the review by Malis and Steele for a discussion of this effect. ${ }^{32}$

Oscillating Knives. We expected that ultrasonic, oscillating knives would produce even better results: Studer and Gnaegi have demonstrated that polystyrene blocks, sectioned with a $45^{\circ} \mathrm{knife}$ oscillating at $2 \mathrm{kHz}$ with $400 \mathrm{~nm}$ amplitude, produced sections compressed by only $3.5 \%{ }^{54} \mathrm{We}$ found that, in addition to reducing compression, oscillating also produced nanostructures of higher quality than do stationary knives. Figures $11 \mathrm{~d}$ and $11 \mathrm{e}$ show gold nanowires cut with a knife without and with oscillation, using the frequency $(2 \mathrm{kHz})$ and amplitude (400 nm) used by Studer and Gnaegi. ${ }^{54}$ The morphology and the edges of the nanowire are smoother if the knife is oscillated. 


\section{Conclusions}

This paper surveyed several materials and processes of thin-film deposition, many of which had not been used with nanoskiving before. From this survey of materials and methods, we found a simple correlation between the propensities of thin evaporated metallic films to fragment, and their bulk values of hardness, tensile strength, elastic modulus, and melting point. The materials that yielded intact nanostructures upon sectioning tended to be soft, compliant, and low-melting. Understanding the exact relationship between the morphology of thin films, their mechanical properties, and their performance in nanoskiving will require further experimentation (e.g., a combination of analysis using TEM, and measurements of the indentation hardness or tensile strength of the thin films). We predict, however, that the rate of defects observed by microtoming thin films would agree qualitatively with measurements of mechanical properties. We also determined the effects of other parameters, such as the orientation of cutting with respect to the embedded thin films, the condition of the diamond knife, and the adhesion of the thin film to the matrix. These experiments provide a practical model for selecting materials, methods of thin-film deposition, and parameters of sectioning, for nanoskiving.

This paper also described factors that could limit the extent to which nanoskiving can be integrated with other techniques. Compression, for example, limits precise registration of arrays with structures produced by conventional lithography and with other arrays produced by nanoskiving. The effect of scoring is more pernicious, particularly if nanoskiving is to be used for production. The effect of accumulated damage to the edge of the knife if used continuously is unknown, but it would require re-sharpening of knives more frequently than is required for sectioning routine biological or inorganic materials. Complete avoidance of hard, inorganic particles requires samples to be molded, coated, and sectioned with assiduous attention to 
cleanliness (or, alternatively, require these steps to be performed in a cleanroom). Despite these shortcomings, nanoskiving is still among the most general methods of fabricating nanostructures with respect to different classes of materials, and is possibly the only method that can pattern multiple materials in the same plane in a single step (as in Figure 9b).

There could be opportunities to exploit what we called "artifacts" in this paper to fabricate structures that cannot be made easily with other methods. For example, controlled fragmentation of nanowires produces nanogaps, which could be used to concentrate electric fields $;{ }^{55}$ deliberate scoring using knives with engineered defects could be used for perforation of nanostructures for the same purpose; and compression and skewing of 2D arrays of nanostructures could be used to generate anisotropic arrays using an isotropic master. ${ }^{42}$

Nanoskiving is the first technique to use mechanical sectioning as the key step in the fabrication and replication of nanostructures singly or in arrays. This report should be useful as nanoskiving develops and for designing other processes of nanomachining in the future.

\section{Methods}

Materials. We obtained Epo-Fix embedding resin from Electron Microscopy Sciences, and UVO-114 from Epoxy Technology, Inc. We obtained metals for evaporation from the Kurt J. Lesker Company. All other chemicals were purchased from Sigma Aldrich. We deposited almost all metals directly onto planar epoxy substrates, which we prepared by mixing Epo-Fix in a ratio (v:v) of base to hardener of 7.5:1 in a sealed centrifuge tube by shaking. We degassed the prepolymer in a vacuum desiccator. We then poured the prepolymer over the polished side of a silicon wafer (we contained the liquid prepolymer using a ring of PDMS) and cured the epoxy for $60^{\circ} \mathrm{C}$ for $2 \mathrm{~h}$. After cooling to room temperature, we peeled the epoxy off the silicon using a 
razor blade. The surface of the epoxy had a value of roughness (rms) of $0.5 \mathrm{~nm}$ (as determined by AFM). To promote adhesion of the thin films to the epoxy substrate, we treated the surface of the epoxy with an air plasma $(100 \mathrm{~W}, 1$ torr, $30 \mathrm{~s})$. The highest-quality films of gold, silver, palladium, and platinum were prepared by template stripping. ${ }^{45}$ In this procedure, the film was evaporated on a silicon wafer and peeled off by curing epoxy against the evaporated film.

Electron-Beam Evaporation. We evaporated films with in a chamber with a base pressure of $1 \times 10^{-6}$ torr, an accelerating voltage of $10 \mathrm{kV}$, a filament current of $0.6-1 \mathrm{~A}$, and rates of deposition of $\sim 1 \AA / \mathrm{s}$ for all materials. The substrate was placed $40 \mathrm{~cm}$ above the source.

Sputter Deposition. We sputter-deposited films of platinum, aluminum oxide, ITO, and silicon dioxide using an AJA model ATC sputtering system, which operated at a base pressure of $8 \times 10^{-7}$ torr. We introduced argon into the chamber at a rate of $40 \mathrm{sccm} / \mathrm{s}$. The pressure during deposition was 4 mtorr. The platinum film was deposited at $450 \mathrm{~V}$ (DC) at 50\% power, with a rate of deposition of $3.6 \AA / \mathrm{s}$. The aluminum oxide film was deposited at $198 \mathrm{~V}$ (RF) at $50 \%$ power, with a rate of deposition of $0.1 \AA / \mathrm{s}$. The ITO film was deposited at $198 \mathrm{~V}$ (RF) at 50\% power, with a rate of deposition of $0.6 \AA /$ s. The silicon dioxide film was deposited at $450 \mathrm{~V}$ (DC) at $50 \%$ power, with a rate of $0.12 \AA / \mathrm{s}$.

PECVD. We deposited a film of silicon dioxide by PECVD using a Surface Technology Systems (STS) system operating at a base pressure of $1.2 \times 10^{-5}$ torr and a pressure of 4 mtorr during deposition. DC power (475 V) and RF power (150 V) were running simultaneously during the deposition.

Spin-Coating of Conjugated Polymer Films. We deposited films of P3HT, and BBL and MEH-PPV, were deposited by spin-coating using previously described conditions. ${ }^{22,52} \mathrm{We}$ deposited films of PEDOT:PSS from a $0.65 \%$ dispersion in water (by diluting a $1.3 \%$ dispersion 
as obtained from Aldrich) by spin-coating at a rate of $1 \mathrm{krpm}$ and annealing in a vacuum oven at $125^{\circ} \mathrm{C}$ for $2 \mathrm{~h}$. We prepared a solution of lead sulfide nanocrystals in hexanes by a reported procedure at a concentration of approximately $10^{16}$ nanocrystals/L. ${ }^{56}$ Spin-coating this solution onto an epoxy substrate $(1 \mathrm{krpm})$, followed by a $1 \mathrm{~s}$ exposure to air plasma (100 W, $500 \mathrm{mtorr})$, provided a mechanically resilient 100 -nm-thick film of nanocrystals.

Embedding. We cut strips from the metallic, semiconducting, ceramic, and polymeric films, supported by their epoxy substrates, into strips, $\sim 5 \mathrm{~mm}$ long, and $0.3-1 \mathrm{~mm}$ long. We placed these strips in polyethylene embedding molds (Electron Microscopy Sciences), filled the molds with mixed and degassed Epo-Fix prepolymer, and cured the blocks at $60{ }^{\circ} \mathrm{C}$ for $2 \mathrm{~h}$.

Ultramicrotomy. We sectioned all films with a Leica Ultracut UCT ultramicrotome equipped with a Diatome Ultra $35^{\circ}$ diamond knife with a $6^{\circ}$ built-in clearance angle. An additional, external $6^{\circ}$ clearance angle produced a total cutting angle of $47^{\circ}$. We cut all slabs using a cutting speed of $1 \mathrm{~mm} / \mathrm{s}$ and a programmed thickness of $80 \mathrm{~nm}$ or $100 \mathrm{~nm}$. The Supporting Information of the paper by Xu et al. ${ }^{5}$ contains a description of the cutting process.

\section{Acknowledgements}

This research was supported by the National Science Foundation under award PHY0646094. The authors used the shared facilities supported by the NSF under MRSEC (DMR0213805 and DMR-0820484). This work was performed in part using the facilities of the Center for Nanoscale Systems (CNS), a member of the National Nanotechnology Infrastructure Network (NNIN), which is supported by the National Science Foundation under NSF award no. ECS-0335765. CNS is part of the Faculty of Arts and Sciences at Harvard University. D.J.L. acknowledges a Graduate Fellowship from the American Chemical Society, Division of Organic 
Chemistry, sponsored by Novartis. The authors thank Professors John Hutchinson and Frans Spaepen for helpful discussions, and Qiaobing Xu and Richard Schalek for obtaining sections using the oscillating knife.

\section{References}

1. Xu, Q. B.; Rioux, R. M.; Dickey, M. D.; Whitesides, G. M., Nanoskiving: A New Method To Produce Arrays of Nanostructures. Acc. Chem. Res. 2008, 41, 1566-1577.

2. Xu, Q.; Rioux, R. M.; Whitesides, G. M., Fabrication of Complex Metallic Nanostructures by Nanoskiving. ACS Nano 2007, 1, 215-227.

3. Dickey, M. D.; Lipomi, D. J.; Bracher, P. J.; Whitesides, G. M., Electrically Addressable Parallel Nanowires with $30 \mathrm{~nm}$ Spacing from Micromolding and Nanoskiving. Nano Lett. 2008, $8,4568-4573$.

4. Wiley, B. J.; Lipomi, D. I.; Bao, J. M.; Capasso, F.; Whitesides, G. M., Fabrication of Surface Plasmon Resonators by Nanoskiving Single-Crystalline Gold Microplates. Nano Lett. 2008, $8,3023-3028$.

5. Xu, Q. B.; Bao, J. M.; Rioux, R. M.; Perez-Castillejos, R.; Capasso, F.; Whitesides, G. M., Fabrication of Large-Area Patterned Nanostructures for Optical Applications by Nanoskiving. Nano Lett. 2007, 7, 2800-2805.

6. Gates, B. D.; Xu, Q. B.; Stewart, M.; Ryan, D.; Willson, C. G.; Whitesides, G. M., New Approaches to Nanofabrication: Molding, Printing, and Other Techniques. Chem. Rev. 2005, $105,1171-1196$. 
7. Stewart, M. E. M., M. J.; Yao, J.; Thompson, L. B.; Nuzzo, R. B., Unconventional Methods for Forming Nanopatterns. Proc. IMechE Part N: J. Nanoengineering and Nanosystems 2007, 220, 81-138.

8. Willson, C. G.; Roman, B. J., The future of lithography: SEMATECH Litho Forum 2008. ACS Nano 2008, 2, 1323-1328.

9. Pease, R. F.; Chou, S. Y., Lithography and Other Patterning Techniques for Future Electronics. Proc. IEEE 2008, 96, 248-270.

10. Stewart, M. E.; Anderton, C. R.; Thompson, L. B.; Maria, J.; Gray, S. K.; Rogers, J. A.; Nuzzo, R. G., Nanostructured Plasmonic Sensors. Chem. Rev. 2008, 108, 494-521.

11. Yun, M. H.; Myung, N. V.; Vasquez, R. P.; Lee, C. S.; Menke, E.; Penner, R. M., Electrochemically Grown Wires for Individually Addressable Sensor Arrays. Nano Lett. 2004, 4, 419-422.

12. Cui, Y.; Wei, Q. Q.; Park, H. K.; Lieber, C. M., Nanowire Nanosensors for Highly Sensitive and Selective Detection of Biological and Chemical Species. Science 2001, 293, 12891292.

13. Ramanathan, K.; Bangar, M. A.; Yun, M.; Chen, W.; Myung, N. V.; Mulchandani, A., Bioaffinity Sensing Using Biologically Functionalized Conducting-Polymer Nanowire. J. Am. Chem. Soc. 2005, 127, 496-497.

14. Boettcher, S. W.; Spurgeon, J. M.; Putnam, M. C.; Warren, E. L.; Turner-Evans, D. B.; Kelzenberg, M. D.; Maiolo, J. R.; Atwater, H. A.; Lewis, N. S., Energy-Conversion Properties of Vapor-Liquid-Solid-Grown Silicon Wire-Array Photocathodes. Science 2010, 327, 185-187.

15. Williams, S. S.; Hampton, M. J.; Gowrishankar, V.; Ding, I. K.; Templeton, J. L.;

Samulski, E. T.; DeSimone, J. M.; McGehee, M. D., Nanostructured Titania-Polymer 
Photovoltaic Devices Made Using PFPE-Based Nanomolding Techniques. Chem. Mater. 2008, 20, 5229-5234.

16. Menard, E.; Meitl, M. A.; Sun, Y. G.; Park, J. U.; Shir, D. J. L.; Nam, Y. S.; Jeon, S.;

Rogers, J. A., Micro- and Nanopatterning Techniques for Organic Electronic and Optoelectronic Systems. Chem. Rev. 2007, 107, 1117-1160.

17. Xia, Y. N.; McClelland, J. J.; Gupta, R.; Qin, D.; Zhao, X. M.; Sohn, L. L.; Celotta, R. J.;

Whitesides, G. M., Replica Molding Using Polymeric Materials: A Practical Step Toward Nanomanufacturing. Adv. Mater. 1997, 9, 147-149.

18. Xia, Y. N.; Kim, E.; Zhao, X. M.; Rogers, J. A.; Prentiss, M.; Whitesides, G. M., Complex Optical Surfaces Formed by Replica Molding Against Elastomeric Masters. Science 1996, 273, 347-349.

19. Chou, S. Y.; Krauss, P. R.; Renstrom, P. J., Nanoimprint Lithography. J. Vac. Sci. Technol., B 1996, 14, 4129-4133.

20. Willson, C. G., A Decade of Step and Flash Imprint Lithography. J. Photopolym. Sci. Technol. 2009, 22, 147-153.

21. Xu, Q. B.; Gates, B. D.; Whitesides, G. M., Fabrication of Metal Structures with Nanometer-Scale Lateral Dimensions by Sectioning Using a Microtome. J. Am. Chem. Soc. 2004, 126, 1332-1333.

22. Lipomi, D. J.; Chiechi, R. C.; Dickey, M. D.; Whitesides, G. M., Fabrication of Conjugated Polymer Nanowires by Edge Lithography. Nano Lett. 2008, 8, 2100-2105.

23. Xu, Q. B.; Bao, J. M.; Capasso, F.; Whitesides, G. M., Surface Plasmon Resonances of Free-Standing Gold Nanowires Fabricated by Nanoskiving. Angew. Chem., Int. Ed. 2006, 45, 3631-3635. 
24. Hill, J., The Construction of Timber. London, 1770.

25. Pease, D. C.; Porter, K. R., Electron-Microscopy and Ultra-Microtomy. J. Cell Biol. 1981, 91, S287-S292.

26. Malis, T., Ultramicrotomy for TEM Specimens in Materials Science - Introduction. Microsc. Res. Tech. 1995, 31, 265-266.

27. Antonovsky, A., Ultramicrotomy of Industrial Alumina. Microsc. Res. Tech. 1995, 31, 300-307.

28. McMahon, G.; Malis, T., Ultramicrotomy of Nanocrystallin Materials. Microsc. Res. Tech. 1995, 31, 267-274.

29. Swab, P., Ultramicrotomy of Diamond Films for TEM Cross-Sectional Analysis. Microsc. Res. Tech. 1995, 31, 308-310.

30. Barreto, M. P.; Veillette, R.; Lesperance, G., Development and Application of a Dry Ultramicrotomy Technique for the Preparation of Galvanneal Sheet Coatings. Microsc. Res. Tech. 1995, 31, 293-299.

31. Glanvill, S. R., Ultramicrotomy of Semiconductors and Related Materials. Microsc. Res. Tech. 1995, 31, 275-284.

32. Malis, T. F.; Steele, D., Ultramicrotomy for Materials Science. Mater. Res. Soc. Symp. Proc. 1990, 199, 3-50.

33. Acetarin, J. D.; Carlemalm, E.; Kellenberger, E.; Villiger, W., Correlation of Some Mechanical-Properties of Embedding Resins with their Behavior in Microtomy. J. Electron Microsc. Tech. 1987, 6, 63-79.

34. Jesior, J. C., How to Avoid Compression .2. The Influence of Sectioning Conditions. $J$. Ultrastruct. Mol. Struct. Res. 1986, 95, 210-217. 
35. Matzelle, T. R.; Gnaegi, H.; Ricker, A.; Reichelt, R., Characterization of the Cutting Edge of Glass and Diamond Knives for Ultramicrotomy by Scanning Force Microscopy Esing Cantilevers with a Defined Tip Geometry. Part II. J. Microsc. Oxford 2003, 209, 113-117.

36. Atkins, A. G.; Vincent, J. F. V., An Instrumented Microtome for Improved Histological Sections and the Measurement of Fracture-Toughness. J. Mater. Sci. Lett. 1984, 3, 310-312.

37. Ohring, M., Materials Science of Thin Films, Deposition and Structure. 2nd ed.; Academic Press: San Diego, CA, 2002.

38. Goldstein, J. N., D.; Joy, D.; Lyman, C.; Echlin, P.; Lifshin, E.; Sawyer, L.; Michael, J., Scanning Electron Microscopy and X-Ray Analysis. 3 ed.; Springer: 2003.

39. Villiger, W.; Bremer, A., Ultramicrotomy of Biological Objects - From the Beginning to the Present. J. Struct. Biol. 1990, 104, 178-188.

40. Graper, E. B., Evaporation Characteristics of Materials from an Electron-Beam Gun .2. J. Vac. Sci. Technol., A 1987, 5, 2718-2723.

41. Kan, C. X.; Zhu, X. G.; Wang, G. H., Single-Crystalline Gold Microplates: Synthesis, Characterization, and Thermal Stability. J. Phys. Chem. B 2006, 110, 4651-4656.

42. Pokroy, B.; Epstein, A. K.; Persson-Gulda, M. C. M.; Aizenberg, J., Fabrication of Bioinspired Actuated Nanostructures with Arbitrary Geometry and Stiffness. Adv. Mater. 2009, $21,463-469$.

43. Technical Data Sheet: Epo-fix Cold-Setting Embedding Resin. http://www.emsdiasum.com/microscopy/technical/datasheet/1232.aspx (accessed March 28, 2010).

44. Nagpal, P.; Lindquist, N. C.; Oh, S. H.; Norris, D. J., Ultrasmooth Patterned Metals for Plasmonics and Metamaterials. Science 2009, 325, 594-597. 
45. Weiss, E. A.; Kaufman, G. K.; Kriebel, J. K.; Li, Z.; Schalek, R.; Whitesides, G. M., Si/SiO2-Templated Formation of Ultraflat Metal Surfaces on Glass, Polymer, and Solder Supports: Their Use as Substrates for Self-Assembled Monolayers. Langmuir 2007, 23, 96869694.

46. Jesior, J. C., How to Avoid Compression - A Model Study of Latex Sphere Grid Sections. J. Ultrastruct. Res. 1985, 90, 135-144.

47. Ditlbacher, H.; Hohenau, A.; Wagner, D.; Kreibig, U.; Rogers, M.; Hofer, F.; Aussenegg, F. R.; Krenn, J. R., Silver Nanowires as Surface Plasmon Resonators. Phys. Rev. Lett. 2005, 95, 257403.

48. Pyayt, A. L.; Wiley, B.; Xia, Y. N.; Chen, A.; Dalton, L., Integration of Photonic and Silver Nanowire Plasmonic Waveguides. Nat. Nanotechnol. 2008, 3, 660-665.

49. Xia, Y.; Xiong, Y. J.; Lim, B.; Skrabalak, S. E., Shape-Controlled Synthesis of Metal Nanocrystals: Simple Chemistry Meets Complex Physics? Angew. Chem., Int. Ed. 2009, 48, 60103.

50. Choi, S. Y.; Mamak, M.; Coombs, N.; Chopra, N.; Ozin, G. A., Thermally Stable TwoDimensional Hexagonal Mesoporous Nanocrystalline Anatase, Meso-nc-TiO2: Bulk and CrackFree Thin Film Morphologies. Adv. Funct. Mater. 2004, 14, 335-344.

51. Cademartiri, L.; von Freymann, G.; Arsenault, A. C.; Bertolotti, J.; Wiersma, D. S.; Kitaev, V.; Ozin, G. A., Nanocrystals as precursors for flexible functional films. Small 2005, 1, $1184-1187$.

52. Lipomi, D. J.; Ilievski, F.; Wiley, B. J.; Deotare, P. B.; Loncar, M.; Whitesides, G. M., Integrated Fabrication and Magnetic Positioning of Metallic and Polymeric Nanowires Embedded in Thin Epoxy Slabs. ACS Nano 2009, 3, 3315-3325. 
53. Lipomi, D. J.; Kats, M. A.; Kim, P.; Kang, S. H.; Aizenberg, J.; Capasso, F.; Whitesides, G. M., Fabrication and Replication of Single- and Multicomponent Nanostructures by Replica Molding and Mechanical Sectioning. Accepted to ACS Nano.

54. Studer, D.; Gnaegi, H., Minimal Compression of Ultrathin Sections with Use of an Oscillating Diamond Knife. J. Microsc. Oxford 2000, 197, 94-100.

55. Cubukcu, E.; Yu, N. F.; Smythe, E. J.; Diehl, L.; Crozier, K. B.; Capasso, F., Plasmonic Laser Antennas and Related Devices. IEEE J. Sel. Top. Quantum Electron. 2008, 14, 1448-1461. 56. Ghadimi, A.; Cademartiri, L.; Kamp, U.; Ozin, G. A., Plasma within Templates: Molding Flexible Nanocrystal Solids into Multifunctional Architectures. Nano Lett. 2007, 7, 3864-3868. 
Figure 1. Schematic representation of the defining step of nanoskiving: mechanical sectioning of microfabricated structures with an ultramicrotome to replicate arrays of nanostructures embedded in thin polymeric slabs. 


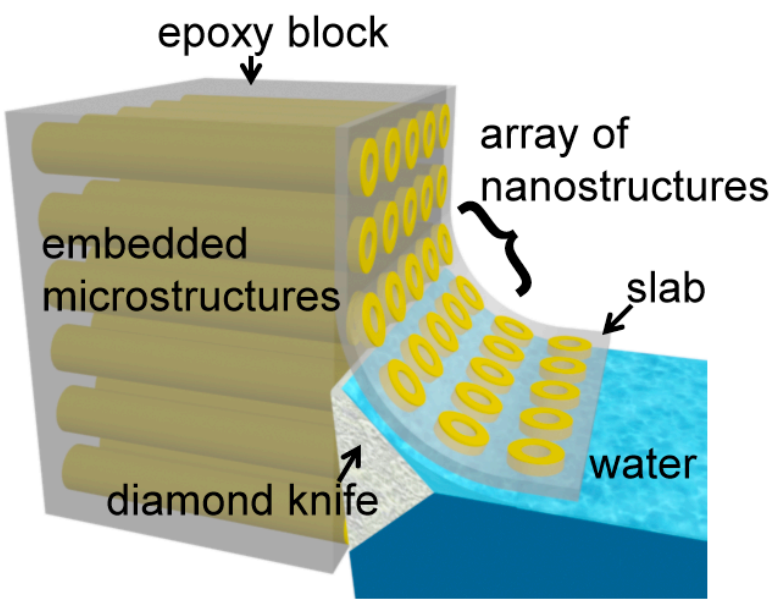

Figure 1. 
Figure 2. Summary of the process used for fabricating nanowires of loosely defined length (> $100 \mu \mathrm{m}$ ) by sectioning thin films. (1) A piece of flat epoxy served as the substrate for deposition of a metallic, polymeric, semiconducting, or oxide film. (2) A rough cut provided a strip of this film supported by epoxy, which we embedded in additional epoxy (3). (4) Ultrathin sectioning (nanoskiving) and removal of the epoxy matrix formed nanowires in which each dimension was controlled by a different step of the process. 
1) Deposit metallic, polymeric, semiconducting or oxide film on flat epoxy substrate:

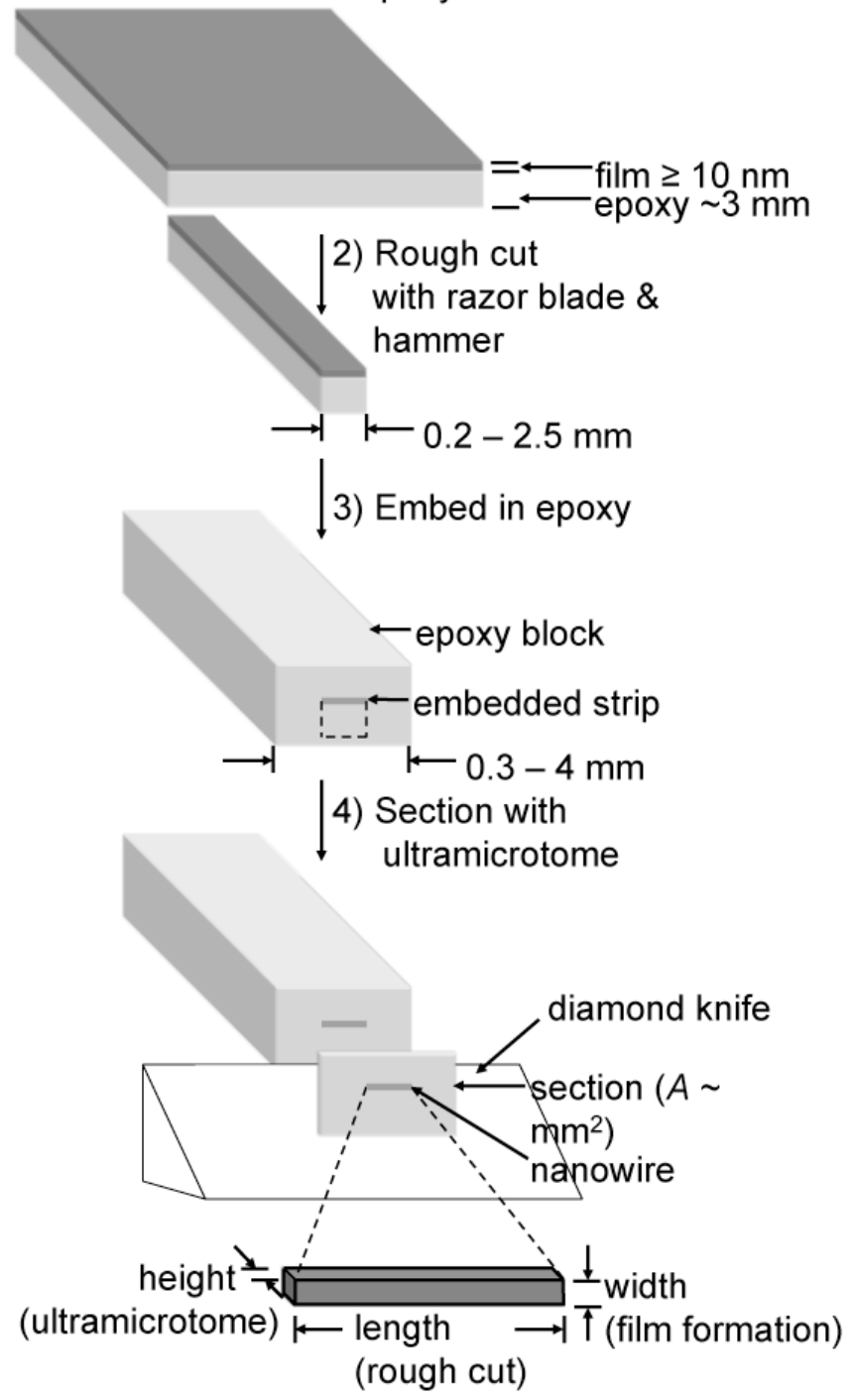

\section{Figure 2.}


Figure 3. Summary of the process used to generate two-dimensional arrays of metallic crescentshaped nanoparticles. (1) Soft lithographic molding afforded an array of epoxy nanoposts. (2) Shadow evaporation, using a collimated source, deposited metal roughly halfway around the circumferences of the nanoposts. (3) Additional epoxy embedded the entire structure. (4) The ultramicrotome sectioned the embedded array into manipulable slabs containing arrays of metallic crescents. 
1) Prepare epoxy nanopost

13) Embed in epoxy
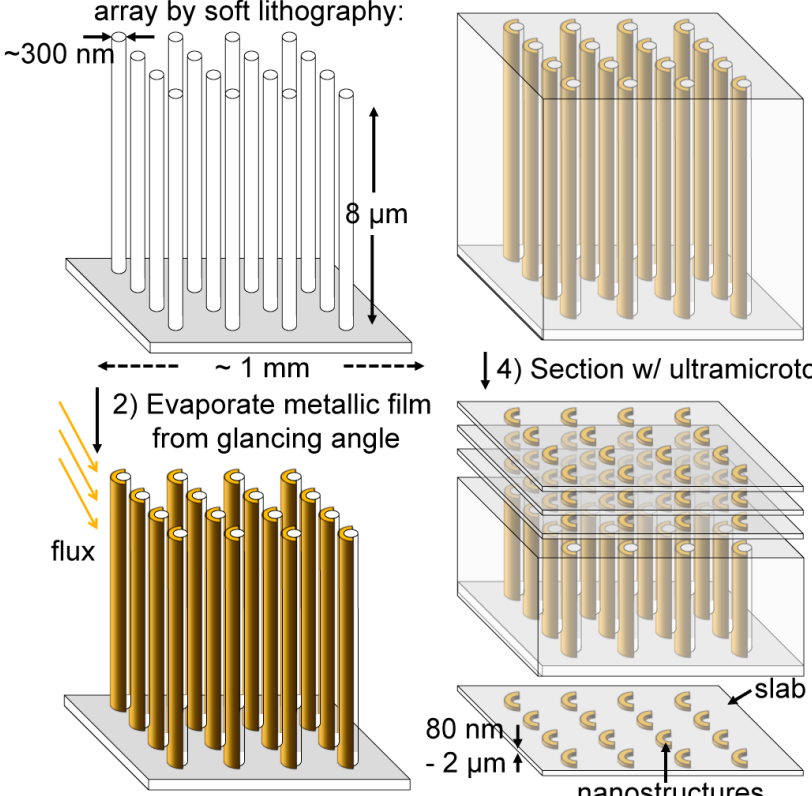

14) Section w/ ultramicrotome

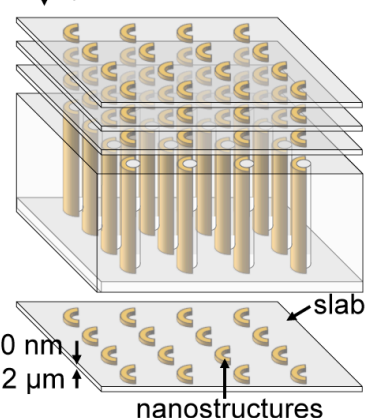

Figure 3. 
Figure 4. Schematic drawings of two mechanisms proposed for sectioning with an ultramicrotome. (a) In "true" or "shear" sectioning, the edge of the knife maintains contact with both the facet of the block and the underside of the epoxy slab. This mechanism produces a region of intense shearing, which is responsible for shear lamellae that are visible in micromachined chips of steel. This mechanism operates for metals and soft materials. (b) The mechanism of crack initiation and propagation is active for brittle materials, such as ceramics. The orange circle highlights the location within the sectioning process where the two models are different. 


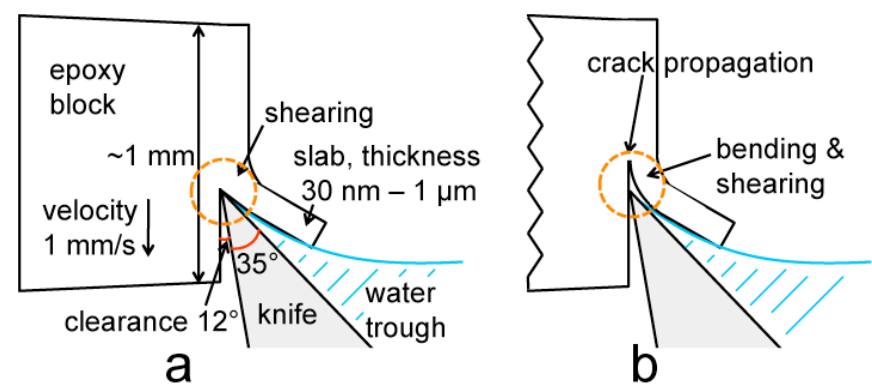

Figure 4. 
Figure 5. Scanning electron microscope (SEM) images of metallic nanowires formed by sectioning thin metallic films deposited by electron-beam evaporation (all except $\mathbf{h}$ and $\mathbf{j}$ ), sputter deposition (h), and solution-phase chemical growth (j). Metals are arranged by atomic mass. Soft and compliant materials - aluminum, copper, palladium, silver, gold, lead, and bismuth — formed long, intact nanowires over distances $>100 \mu \mathrm{m}$. Hard and rigid materialstitanium, nickel, and platinum—-tended to fracture. 


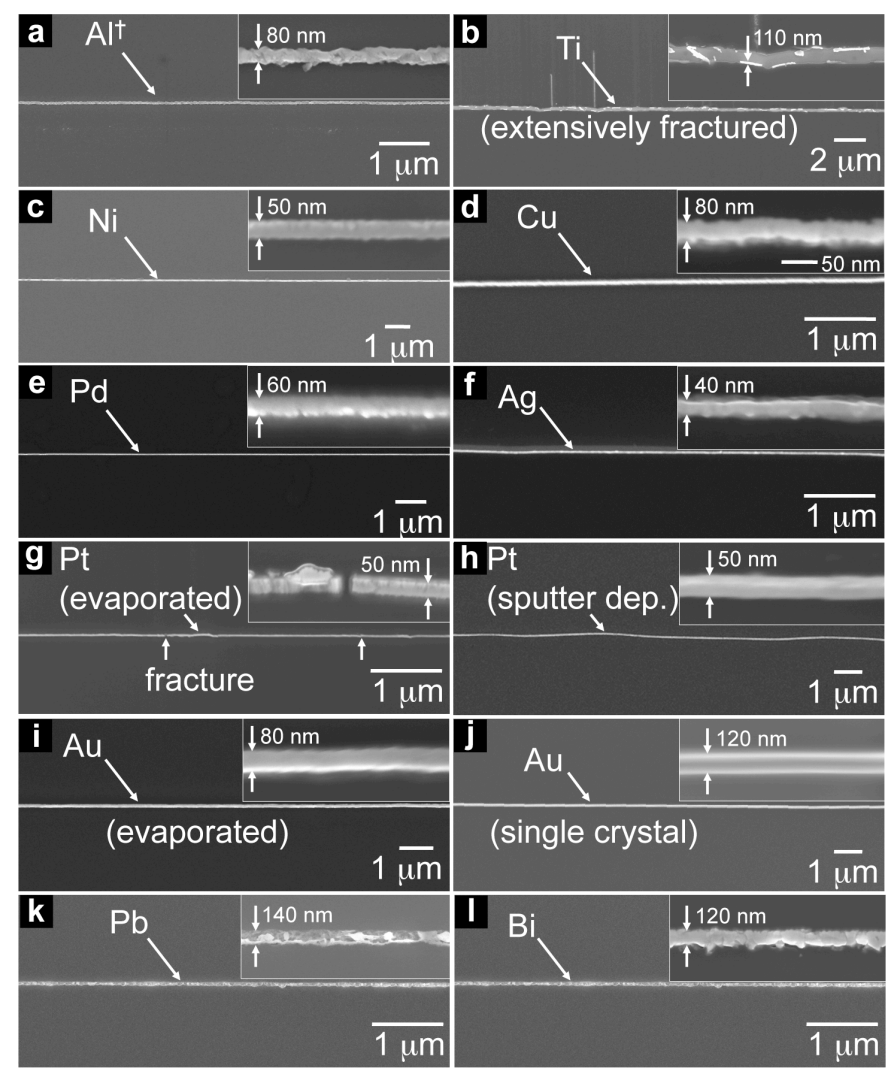

Figure 5. 
Figure 6. Scanning electron micrograph (top) of a long gold nanowire that was electrically continuous over a span of $1.8 \mathrm{~mm}$. The plot (bottom) shows current density v. voltage of the nanowire across the span of $1.8 \mathrm{~mm}$. 


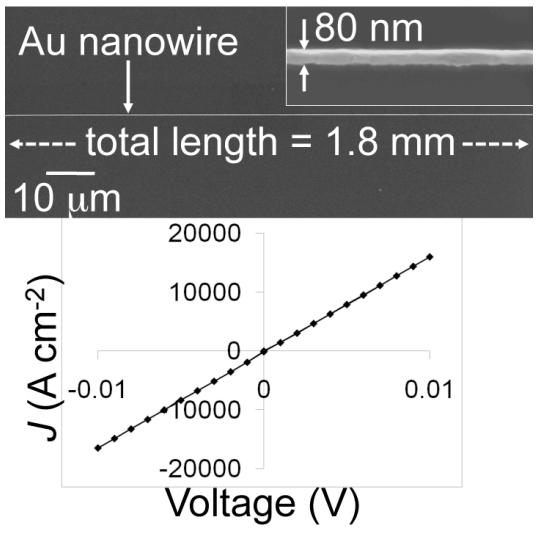

Figure 6. 
Figure 7. The effects of the direction of cutting on the morphology of nanostructures and the extent of fragmentation. (a) A palladium nanowire (NW) sectioned with the direction of cutting perpendicular to the edge of the film. (b) A nanowire sectioned with the direction of cutting parallel to the edge of the film. Sectioning parallel to the edge produces two effects: a rougher morphology (insets of a and b) and a higher frequency of fragmentation. (c) The effect of speed of sectioning on the frequency of fragmentation in platinum nanowires sectioned parallel to the plane of the film. There was no effect from $0.1 \mathrm{~mm} / \mathrm{s}$ to $8 \mathrm{~mm} / \mathrm{s}$. With a speed of $10 \mathrm{~mm} / \mathrm{s}$, buckling accommodated some of the compressive strain, and had the effect of reducing the frequency of defects. 
a

Direction of cutting

perpendicular to edge
of film:

b

Direction of cutting parallel to edge
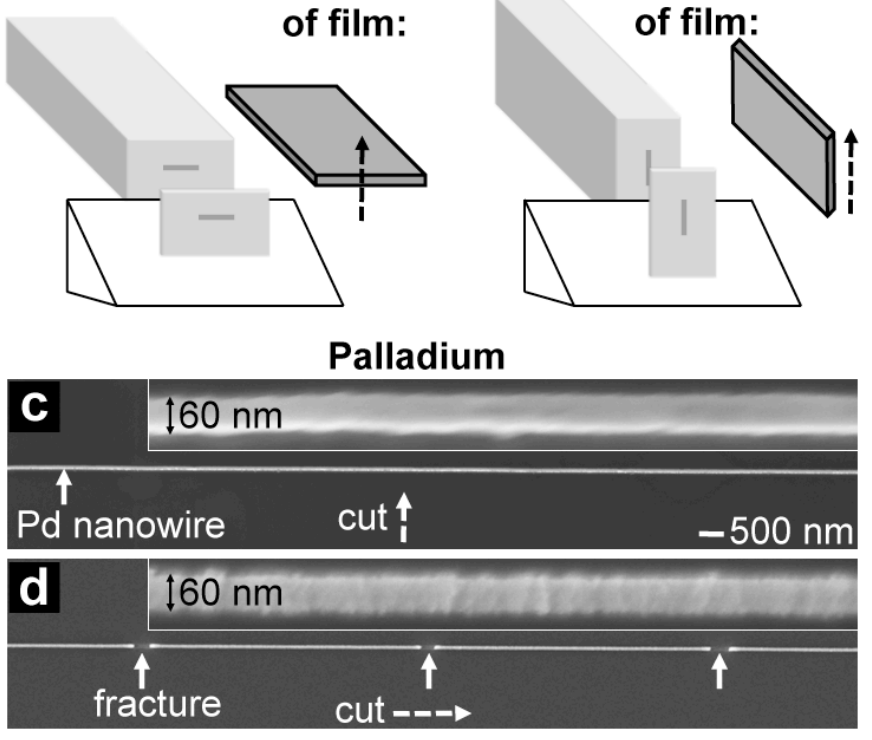

e

\section{Platinum}

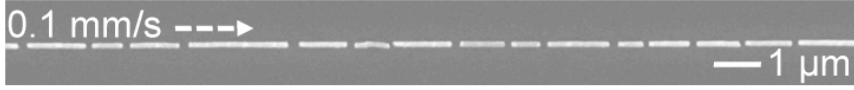

\section{$0.5 \mathrm{~mm} / \mathrm{s}$}

\section{$1 \mathrm{~mm} / \mathrm{s}$}

$5 \mathrm{~mm} / \mathrm{s}$

\section{$8 \mathrm{~mm} / \mathrm{s}$}

$10 \mathrm{~mm} / \mathrm{s}$

Figure 7. 
Figure 8. Nanowires of semiconductors, ceramics, and conjugated (semiconducting and conducting) polymers. All materials were deposited by e-beam evaporation unless otherwise noted. Among amorphous, evaporated elemental semiconductors, germanium remained intact (a), while silicon fragmented (b). All films of alumina and ITO deposited by evaporation (c and g) and sputter deposition (not shown) were fragmented. The ability to form intact nanowires of $\mathrm{SiO}_{2}$ depended strongly on the method used for deposition: sputter-deposited films remained intact, while evaporated films, and those deposited by plasma-enhanced chemical-vapor deposition (PECVD) fragmented. Spin-coated films of lead sulfide nanocrystals (h) formed intact nanowires, as did all conjugated polymer films tested. The film of PEDOT:PSS adhered poorly to the epoxy matrix, but it did not fragment. 


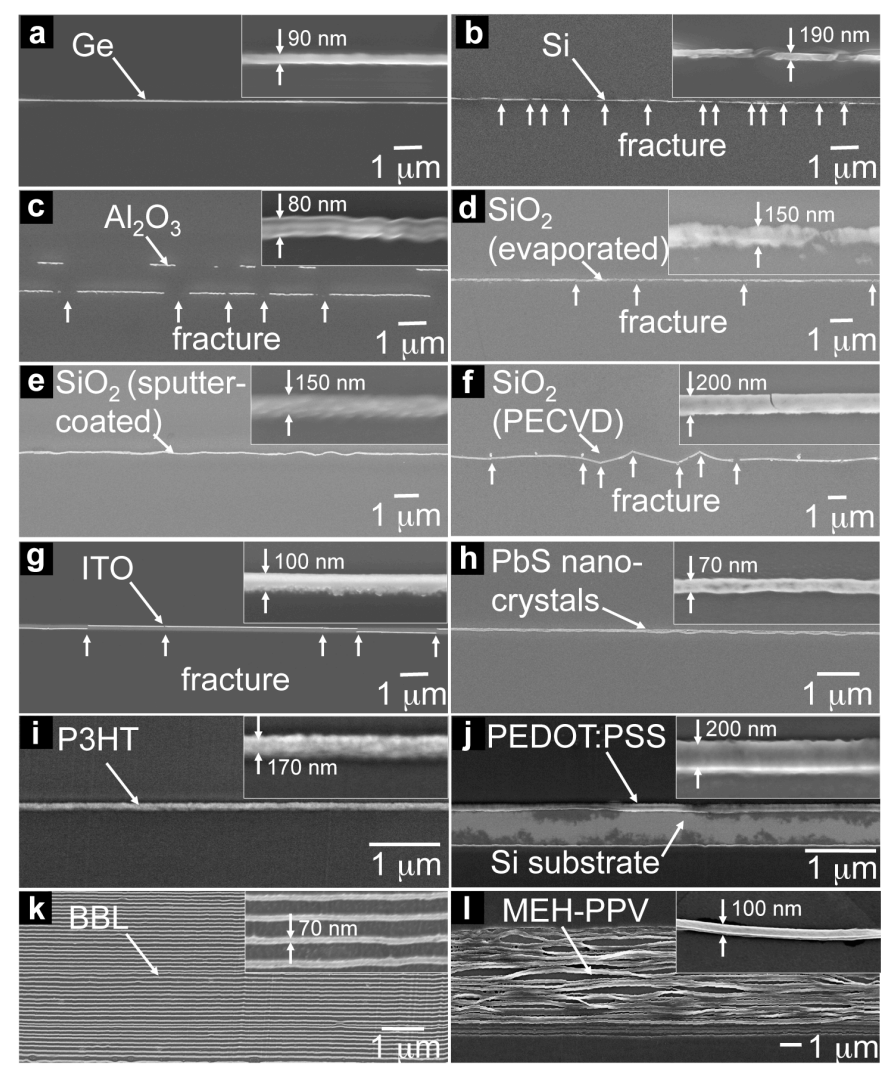

Figure 8. 
Figure 9. (a) An array of gold-coated epoxy nanoposts (the product of step 2, Figure 2). The posts are $8 \mu \mathrm{m}$ tall, and $250 \mathrm{~nm}$ in diameter, at the top. (b) An array of platinum crescent-shaped nanoparticles. (c) An array of counterfacing crescents of silver and silicon. (d) A square array of nanostructures was compressed during the cutting operation. Panels (b) and (c) adapted with permission pending from [Lipomi 2010, unpublished]. Copyright 2010, American Chemical Society(?) 

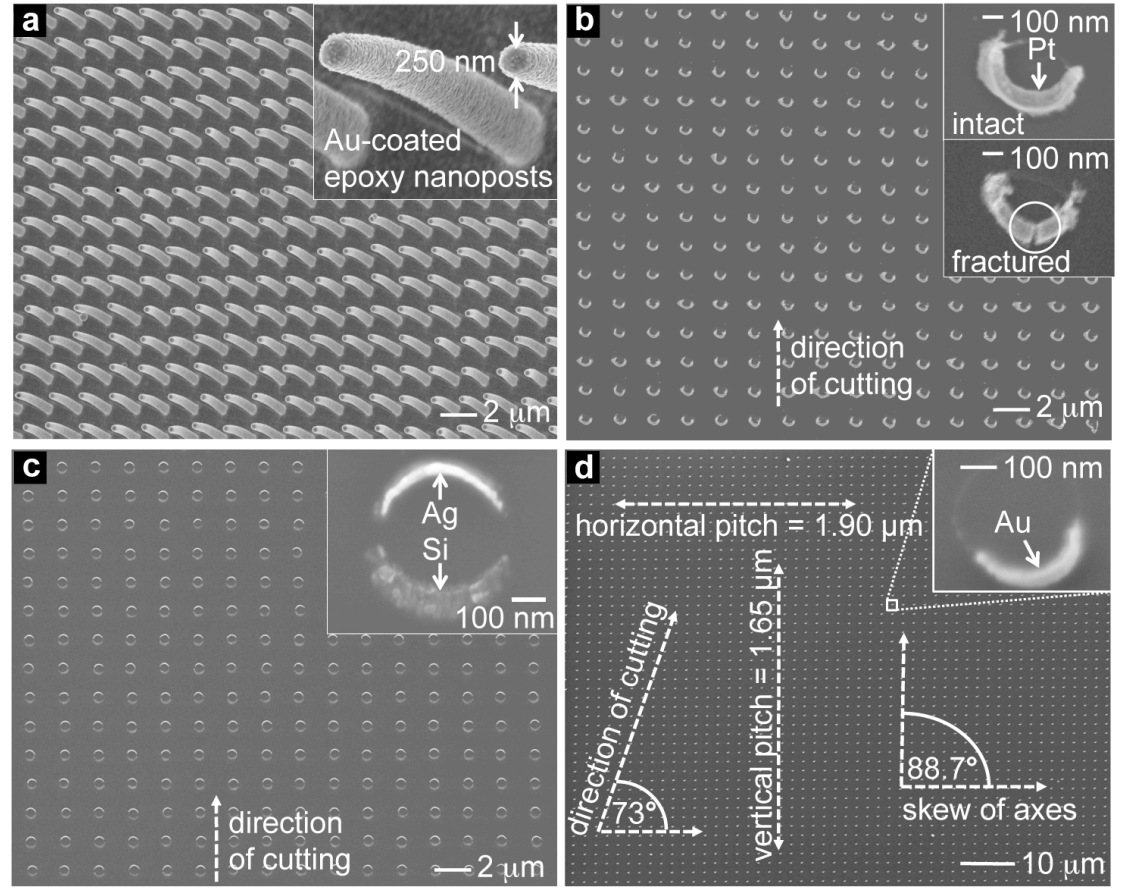

Figure 9. 
Figure 10. Summary of findings and predictions regarding the abilities of elements, oxides, polymers, and nanocrystals to form nanowires by sectioning thin films. 


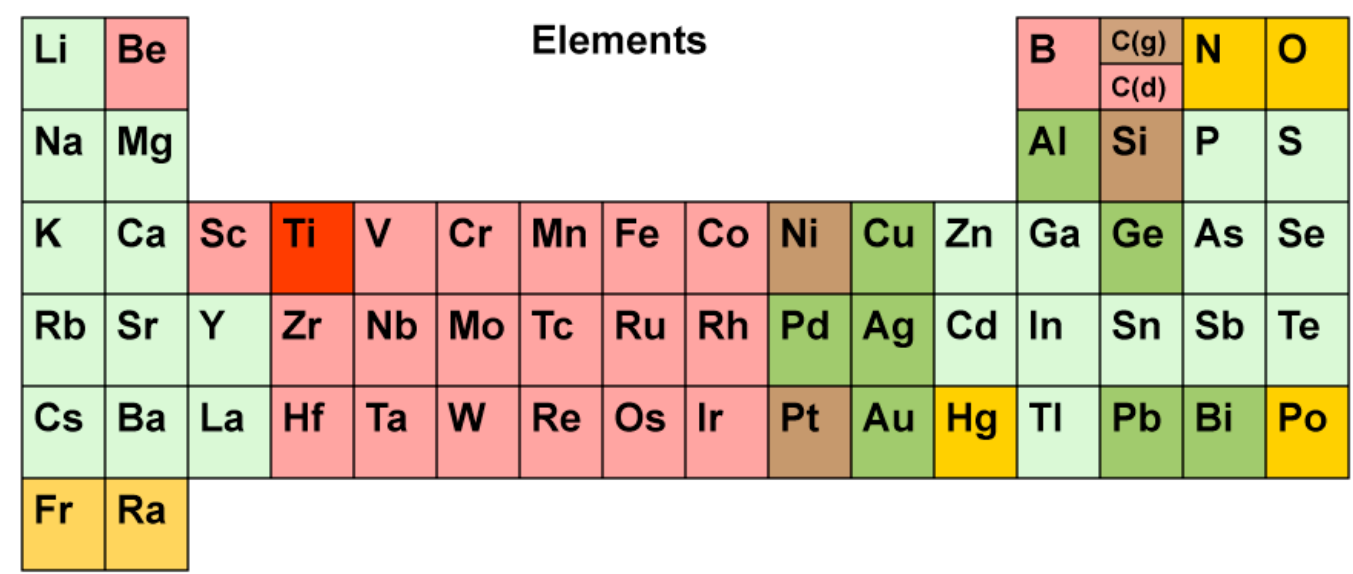

Oxides Conjugated Polymers Nanocrystals Legend:

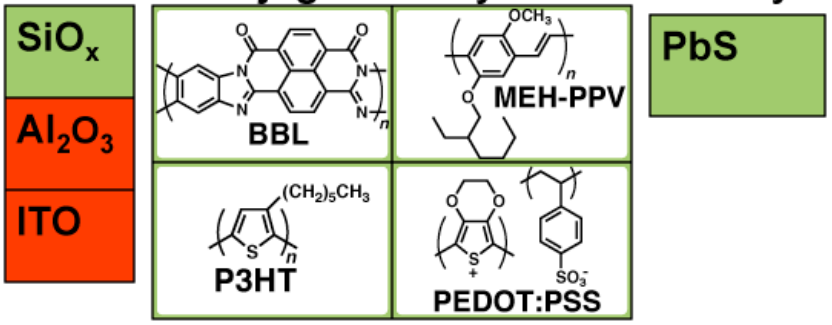

\begin{tabular}{|l|}
\hline Intact \\
\hline Predicted to be intact \\
\hline Borderline \\
\hline Predicted to be fragmented \\
\hline Fragmented \\
\hline Not applicable \\
\hline
\end{tabular}

Figure 10. 
Figure 11. Examples of artifacts of the process of sectioning that are deleterious to the structures produced. (a) A divot in the edge of the knife produced the score on the surface of the epoxy matrix. The score damaged the gold nanowire at the point of intersection. (b) A defect in an aluminum nanowire and concomitant delamination of the nanowire from the epoxy matrix. The silicon support used for imaging by SEM is visible in the gap. (c) Poor adhesion of a nickel film to the epoxy matrix caused delamination of the nanowire from the slab. Delamination caused both sides of the nanowire to be supported unevenly during cutting, and the nanowire broke. (d) Image of a gold nanowire sectioned with a knife, without supersonic oscillation. (e) The same gold nanowire cut with oscillation. The morphology and the roughness of the nanowire cut with oscillation are smoother than the nanowire cut using a stationary knife. 

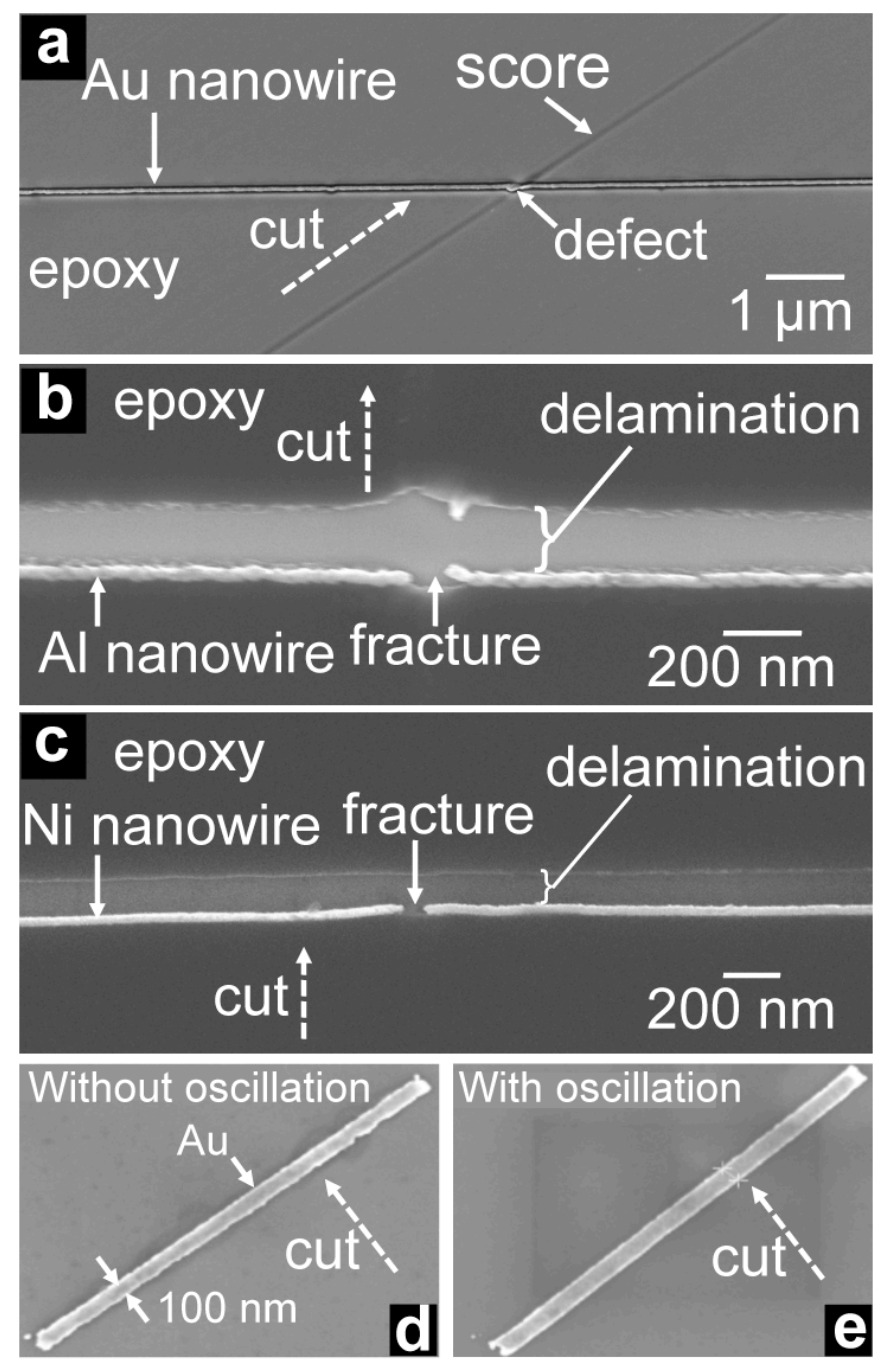

Figure 11. 